\title{
Capítulo 5 \\ Comunicación, identidad y conflictos en el mundo juvenil
}

ste capítulo gira en torno a las relaciones sociales y la autoi-
magen de los estudiantes entrevistados. Estas cuestiones resultaron decisivas para comprender -poniéndolo en términos de performance social (Alexander, 2005b)- cómo es que los participantes se veían a sí mismos en tanto que actores sociales individuales y colectivos, de qué modo las tecnologías digitales complejizaban su vida afectiva y cómo creían ellos que dichos conflictos podían llegar a resolverse. Estos hallazgos sobre la comunicación, la identidad y los problemas típicos del mundo juvenil están organizados en dos secciones. La primera recoge los aportes de los estudiantes respecto a la mediación de las tecnologías digitales en sus relaciones con familiares, amigos y parejas. En la segunda sección se hace alusión a las definiciones que los participantes aportaron sobre sí mismos en tanto que jóvenes y estudiantes, pero además se reseñan algunas discusiones en torno a los principios que, según ellos, deberían orientar la relación de las personas con las tecnologías digitales. 


\section{La comunicación en el mundo juvenil: Entre la proximidad a distancia y la banalidad del encuentro presencial}

En el Capítulo 3, se indicó que buena parte de las discusiones giraron en torno a la comunicación mediada por tecnologías digitales. Según los participantes, diversos dispositivos y plataformas intervienen poderosamente en las formas como se produce la comunicación en el mundo actual. De hecho, el uso de estos aparatos hace que las personas adopten cada vez más una actitud comunicativa de ausencia-presente y/o de presencia-ausente. Con base en esos planteamientos, en esta sección se intentará mostrar de qué modos lo dicho por los estudiantes sobre la comunicación actual se concreta en el universo de sus relaciones personales, en específico con sus familias, amigos y parejas. Esto para mostrar que las tecnologías y los medios digitales no solo juegan un papel importante en los tiempos de ocio y de estudio, sino que su uso implica sobre todo unos cambios dramáticos, desde el punto de vista estudiantil, en la comunicación y en las relaciones sociales.

Como se advierte en la Figura 5, la comunicación mediada digitalmente equivale, en el mundo juvenil, al imperativo de estar conectados. La conectividad define, entonces, las condiciones tanto para la existencia social como para la comunicación y las relaciones de sociabilidad.

Cuando se abordó el tema de las relaciones y la comunicación con familiares, amigos y parejas, el discurso de los estudiantes tendió a oscilar entre dos polos: la superación de las distancias físicas vs. el vaciamiento de sentido en las relaciones presenciales. Por un lado, algunos participantes manifestaron que las tecnologías digitales les permitían superar las distancias físicas en la comunicación. Esto, según dijeron, les resultaba especialmente significativo ya que les daba la posibilidad de mantener un vínculo con sus familiares y amigos en el exterior. Por otra parte, otros indicaron que 
la proximidad que se gana en las relaciones a distancia se pierde en las relaciones presenciales. El tiempo y las conversaciones cara a cara que tienen lugar con amigos y sobre todo con las parejas se antojan cada vez más superficiales. El hecho de estar conectados les plantea dilemas. En las subsecciones que vienen se abordarán con más detalle estas cuestiones.

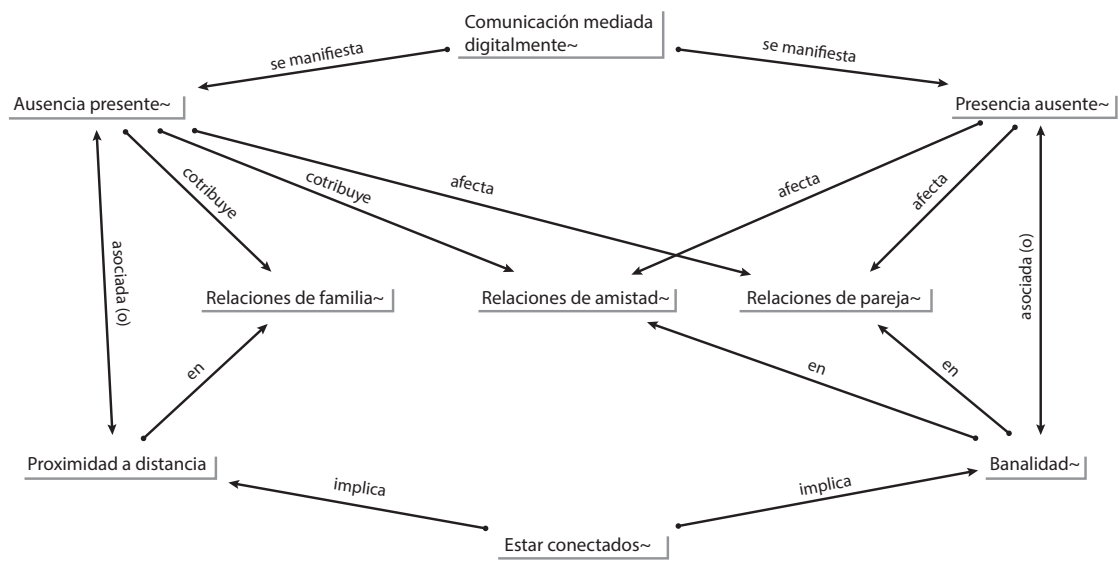

Figura 5. Comunicación mediada digitalmente y relaciones sociales en el mundo juvenil.

Fuente: elaboración propia.

Estar conectados: pauta de la comunicación en el mundo juvenil

Según afirmaron los participantes, la forma en que ellos mismos se comunican y se relacionan tiene mucho que ver con estar conectados. Este concepto remite, para ellos, a una posibilidad de comunicación y/o de encuentro presencial que puede o no realizarse en el futuro inmediato, pero que sobre todo tiene que ver con un grado de disponibilidad a través del móvil o de redes sociales. Así, más que una búsqueda constante de interacciones, para los estudiantes la comunicación se basa en estar disponible 
ininterrumpidamente, de tal forma que sea posible contactar, a través del móvil o de redes sociales, a quienes componen el propio círculo social. Estos fueron algunos planteamientos en los que se pudo entrever lo que para los participantes significa estar conectados:

-Es que ahí [en Facebook] eso [tener muchos contactos] es lo primordial (...) uno busca en Facebook y ahí están conectados (...). A mí me escriben por 'Face' y respondo más rápido. (G.1, p. 12, r. 6)

-Si no estamos acá en la universidad estamos en Facebook y pues desde ahí se conecta uno. (G. 4, p. 2, r. 1)

En la parte de socialización y de comunicarme con mis amigos todo el tiempo estamos conectados, por eso nunca nos llamamos ni nada. Y pues el tiempo ha cambiado y todos hacemos eso; de los compañeros yo no llamo a ninguno de la universidad sino todo es por redes sociales, y pues como todos tienen Facebook pues todos dicen: "no pues digámonos por Facebook en la noche". (G. 6, p. 2 , r. 7 )

Al pedirles una valoración de sus experiencias comunicativas, algunos participantes afirmaron que la comunicación mediada por móviles y redes sociales les resultaba más sencilla que la comunicación presencial. Esto, a su juicio, se debía a que en una conversación online no se tiene la presión de la presencia física del otro, lo que permite superar la timidez y organizar mejor las ideas. Según ellos:

$-(. .$.$) a veces resulta que es más fácil decir la cosas por Internet$ porque no te están viendo (...) estar hablando por un teléfono es más agradable y no lo están viendo a uno, pero lo están oyendo. Por Internet no hay nada de contacto [físico] (...) cuando uno está chateando uno está como más seguro de uno. (G. 6, p. 2, r. 6)

-Se pierden las relaciones personales, pero se ganan las relaciones a distancia. Es así: porque está lejos entonces yo le escribo, pero ya de cerca no. (G. 2, p. 5, r. 4) 
-(...) cualquier persona es valiente frente a una pantalla (...) pero de frente es muy diferente porque se siente la presión de la otra persona, porque no se tiene tiempo de pensar una respuesta para escribirla. (G. 10, p. 4, r. 8)

Por otra parte, algunos estudiantes afirmaron que estos nuevos protocolos han debilitado las competencias sociales y la búsqueda de contacto presencial. De ahí las mutaciones, según ellos, en la forma como se entienden y construyen las relaciones con los otros. En muchos casos la comunicación y las relaciones terminan reducidas a intercambios esporádicos de mensajes vía Internet, o visitas al perfil de usuario en determinadas plataformas, pues para ellos tiene cada vez menos sentido un encuentro cara a cara. De ese modo, las amistades terminan debilitándose, como queda planteado en las siguientes observaciones:

-Mis relaciones con mis amigos sí han cambiado, ahora son más que todo por Internet. Yo ya no me veo con ellos y se alejaron mucho, ahora simplemente hablamos [a través de redes sociales]. Con otros la comunicación se perdió del todo y ya no tengo contacto personal con ellos. (G. 2, p. 5, r. 1)

-El mundo cada vez es más sistematizado y el contacto personal es mucho menor. Ya, por ejemplo, el contacto entre una persona y la otra se resume con ir al perfil de Facebook y ya. (G. 3, p. 7, r. 4)

Podría afirmarse, entonces, que la conectividad como pauta para relacionarse y comunicarse permite superar las distancias espaciales, pero hace que se pierda profundidad en el encuentro presencial. Por un lado, se valoran las posibilidades de la comunicación actual teniendo como referencia la promesa de una proximidad, pero por otro se advierte la amenaza de la banalización en sus relaciones presenciales. Esta valoración, en clave de doble filo, se evidencia en las siguientes intervenciones: 
-Sí, tiene su lado bueno y malo, como dice ella. Uno puede hablarse con las personas con que uno tenía una amistad. Por ejemplo, con los amigos del colegio que se fueron [de la ciudad o del país]: tú hablas con ellos por chat, video chat o pin. Pero con los que no se han ido pues... No sé, ahora en general es como por chat, ya no tiene uno los superamigos del colegio (...) ya no compartimos ni una tarde juntos. (G. 2, p. 5, r. 6)

-En el caso de mis amigos me parece mejor así [por Internet]: los puedo tener a todos ahí, puedo hablar con todos. Pero ya en relaciones personales en cuanto a novio pues es que no sé, todo mundo tiene pin o WhatsApp; no quieren llamar, se pierde eso. Entonces [dicen]: “'para qué nos vamos a ver? No, hablemos toda la tarde por ahí. Entonces, ya como que el contacto cambia. (G. 2, p. 5, r. 5)

\section{Relaciones sociales, entre la proximidad a distancia y la banalidad}

Como se afirmaba líneas arriba, la comunicación digitalmente mediada en el ámbito juvenil dio lugar a un debate muy interesante sobre las relaciones sociales. Se insistió bastante en que la posibilidad que ofrecían las tecnologías digitales de superar las barreras espaciales resultaba especialmente reconfortante cuando se trataba de comunicarse con familiares que vivían en el exterior, como consta en las siguientes intervenciones:

-La tecnología es importante porque puede (...) acercarnos a la familia cuando la tenemos en el exterior. [Las tecnologías] ayudan a que [las familias] se acerquen de manera muy significativa. (G. 2, p. 1, r. 6)

-Sí, [el Internet] es lo más importante porque, digamos, si mi familia está muy lejos, por la necesidad de tenerlos cerca uso más el Internet (...) me conecto por el Skype desde el computador. (G. 2, p. 4, r. 8) 
-Los equipos electrónicos (...) facilitan en el ambiente familiar la comunicación con familiares en el exterior. Yo con mi celular hago una video llamada o desde mi computador (...). (G. 3, p. 2, r. 5)

-Yo creo que en las relaciones sociales es benéfico: los que tenemos familiares en el extranjero, obviamente son personas a las que se extraña y personas a las que por medio de las redes sociales o Internet los sentimos como si estuvieran a nuestro lado. (G. 10, p. 4, r. 5)

-Yo no soy de acá [Bogotá] y aunque no tengo familia en otro país, estando en el mismo país puedo sentirlos cerca con lo que dicen: por un momento con un clic verles la cara algún día, por unos minutos; reconforta el corazón y las distancias se acortan por minutos. (G. 10, p. 4, r. 6)

Otra situación que se valoró positivamente fue que las tecnologías digitales brindan el acceso a información actualizada sobre los demás miembros de la familia y permiten contactarlos fácilmente. Según algunos participantes, teléfonos móviles y determinadas aplicaciones resultan fundamentales para el monitoreo y la comunicación entre padres e hijos. De esa forma, según dijeron, se minimizan los riesgos (robos y abusos, por ejemplo) a los que, sobre todo los más jóvenes, están expuestos en ciudades como Bogotá:

-Yo, por ejemplo, que tengo una mamá muy sobreprotectora y un papá también [sobreprotector], yo [les escribo]: “mami ya llegué; mami no sé qué. Entonces me sirve mucho [el móvil]. (G. 2, p. 4, r. 5)

-Antes, incluso, un teléfono móvil lo tenían las personas adultas; hoy lo tienen los niños. Si la mamá se quiere comunicar con los niños para ver cómo están, o hay una noticia trágica de un sector $x$, sencillamente marca el número y ya, listo, se comunica con su hijo en menos de un minuto. Entonces, genera mucho acercamiento esa posibilidad de hablar continuamente con quien sea (...). (G. 3, p. 3, r. 5) 
Ahora bien, si para algunos de los participantes las tecnologías digitales permiten superar las distancias y generan un efecto de proximidad no presencial, pareciera que para otros estas producen un efecto nocivo en las relaciones y los ámbitos donde el contacto físico y la presencialidad son fundamentales. Las referencias constantes a cómo se han venido debilitando las relaciones de amistad y de pareja llevó a formular el código "banalidad". Las siguientes intervenciones recogen lo que manifestaron los estudiantes respecto a cómo las relaciones presenciales resultan vaciadas de significado y emoción por la comunicación mediada digitalmente:

-Tampoco me gustan algunas de esas [tecnologías] (...). Lo que yo pienso que es la sociedad, digamos, el hablar con otras personas, el comunicarse, ya se ha acabado bastante. Como ya lo mencionó el compañero, ya no hay una charla presencial, sino una charla por el celular. (G. 3, p. 4, r. 5)

-Yo creo que el mundo ha cambiado drásticamente con el uso de las tecnologías. O sea, uno ve cada día que es muchísimo más el cambio que se da, más que todo en la parte social porque yo creo que se ha generado un rompimiento serio de las relaciones entre las personas. Yo siento que las personas que tienen un uso masivo de las tecnologías prácticamente están aisladas de las comunidades con las que comparten (...) se ve que están tan cerca pero a la vez tan distanciados. Entonces, yo siento que eso ha afectado mucho la parte social; y sí, la gente se siente feliz que las tecnologías estén aplicadas en el mundo porque uno se siente contento que, con el Internet, con el celular, pero en sí las relaciones personales se han deteriorado mucho. (G. 3, p. 7, r. 3)

-Mi opinión sería como que [la tecnología] debilita las [relaciones] locales, al punto que uno pasa más tiempo con las personas que [no] están a su alrededor. Y en el momento que está con otros [físicamente], está comunicándose por otro lado. Si llegas a ser muy obsesivo con el Internet, se cierra tu círculo social por estar comunicándote con otras personas. (G. 9, p. 3, r. 4) 
-Las relaciones sociales actuales, es decir las del plano físico, caen en un vacío de virtualismos. (G. 11, p. 3, r. 2)

En esa línea de reflexiones desencantadas, algunos estudiantes afirmaron que, pese a sofisticación de las tecnologías digitales, el contacto personal con los amigos aún les resulta mucho más significativo. De hecho, según manifestaron, en muchos casos la mediación de la tecnología impide la intimidad y la empatía. Llamó especialmente la atención la forma como algunos estudiantes describieron el contacto presencial, en términos de una experiencia honesta, directa y afectiva:

-(...) ya no se ve tanto la comunicación como de contacto personal. Yo ya, por eso, ni le oigo la voz a la persona, ni sé cómo se expresa porque como estoy ahí chateando... Entonces, si yo me escribo con él todo el tiempo ya no voy a saber cómo se expresa. [Esa persona] puede estar triste y no es lo mismo que me mande una carita triste a que yo vea que está triste. (G. 2, p. 5, r. 1) -(...) cuando una persona se relaciona es cuando está en contacto con el otro en medio físico, se están sintiendo, tocando a la otra persona, sabe cómo es (...). Por medio de estas tecnologías es muy duro saber si con la otra persona se está hablando o qué se está haciendo. (G. 9, p. 3, r. 1)

-(...) una cosa es decirte de frente qué paso y ver tu actitud con lo que me dices que por medio de un chat. En los problemas personales no es lo mismo. Es [mejor] de frente para sentir lo que me estás diciendo y tener como un contacto más directo. (G. 9, p. 5, r. 2).

Respecto al papel de las redes sociales en la banalización de las relaciones personales un estudiante refirió, tomando como caso a Twitter, que la comunicación en esas plataformas se basa en una lógica de validación. Según él, lo que más importa en Twitter no es compartir los pensamientos, sino conseguir seguidores: 
-Una red social que se ha entregado mucho a publicar cualquier estupidez es Twitter: "que tengo frío, que voy a comer" (...). La gente escribe todo lo que hace y pues no le da como un uso adecuado. No sé, es más que todo como la forma de pensar de cada quien, de compartir ideas. Pero no, es más para tener seguidores. (G. 4, p. 6, r. 5)

En esa misma línea otro participante comentó:

-Yo creo que hay, bueno, hay muchas redes sociales en las que uno tiene amigos y todo, pero no es tan bueno como tener el contacto personal en las relaciones y eso lo que hace muchas veces es acabar con esas relaciones. (G. 5, p 2, r. 1)

También se discutió sobre la mediación de las tecnologías digitales en sus relaciones familiares en directa alusión al riesgo de que estas se banalicen. En ese contexto se advirtió que para algunos de ellos las interacciones entre los adultos siguen siendo un modelo que se debe seguir. Para otros, por el contrario, sus padres y familiares han venido adoptando cada vez más la conectividad como pauta comunicativa. Los estudiantes afirmaron:

-En una reunión familiar uno ve a los menores de 25 años pegados a un celular chateando, y los demás, la gente más madura, están es conversando de otra manera. Entonces sí [la tecnología] las afecta [las relaciones sociales] y mucho. (G. 10, p. 4, r. 1)

-Uno está hablando con una persona (...) uno no le pone atención a ella porque está hablando por el Facebook. (...). Yo tengo a mi familia, siempre son así: están conectados por esos aparatos y uno les habla y nada, no contestan. (G. 1, p. 16, r. 17)

-En mi casa, por ejemplo, se da que son muy tecnológicos y en ocasiones llega la hora de la comida y mi mamá por teléfono me escribe "a comer". Entonces uno dice como "¿qué? [risas] ¡si estamos en la misma casa! ¿Qué pasa?” (...) Otra cosa: está uno hablando y nada, cada uno hablando por su lado por el celular. (G. 1, p. 16, r. 18) 
Algunos participantes ofrecieron una explicación alternativa a la de las tecnologías como instrumento de monitoreo familiar y minimización del riesgo por inseguridad. Según ellos, los padres compran tecnología no para cuidar de sus hijos, sino con el fin de distraerles y tenerles entretenidos. La mediación de las tecnologías se convierte, entonces, en una forma de control volcada no tanto a la seguridad, sino más bien a un uso del tiempo libre que no demande una participación parental activa. Para la muestra, esta seguidilla de intervenciones:

-En la casa en la que los dos [padres] trabajan dejan al niño solo. Entonces, ¿qué van a hacer para que el niño no salga? Le compran el iPad. El niño tiene 5 años, y como el niño no sale, y los papás trabajan todos los días, y el niño quiere salir los fines de semana, pero ellos no porque están cansados, porque tienen trabajo, y el niño es el que se siente solo. ¿Y qué es lo que necesita [según los papás]? pues el contacto con las tecnologías (...). Entonces yo lo veo más de cómo los papás lo quieren manipular a uno por medio de las tecnologías.

-Mis papás trabajan y en una ocasión me compraron un perro. Y claro, yo era feliz con mi perro porque me sentía acompañado, lo consentía y todo. Y pues no era muy juicioso que digamos. Por eso mi mamá un día decidió regalarlo y claro, eso fue fatal. Entonces, claro, yo estaba mal y pues ¿que tocó? Con la televisión, porque no podía salir, porque estaba solo y no tenía nada más que hacer. Entonces sí, es como eso. (G. 1, p. 17, r.8 y 9)

En lo que atañe a las relaciones de amistad los estudiantes reconocieron que las redes sociales y los teléfonos móviles son bastante útiles para organizar encuentros presenciales. Sin embargo, algunos manifestaron su disconformidad con el uso de estas tecnologías mientras se desarrollan reuniones presenciales. A su juicio, la conectividad constante termina por aislar al individuo de las personas que se encuentran físicamente cerca, como se aprecia en las siguientes intervenciones: 
-(...) cuando es el momento de compartir pues es a compartir. Cuando acompañé a [nombre de un amigo] al cumpleaños había un compañero ahí metido en el celular y le dije: “¡oye! es una falta de respeto, estamos aquí en una reunión y te invitamos para que compartieras". (G. 3, p. 7, r. 5)

-En ese momento, su vida social [la del individuo conectado] es asocial porque está de cuerpo presente, pero a la vez no porque está distrayéndose en otras cosas. Incluso, recuerdo que una vez fui a un restaurante y dos personas estaban así tecleando; o sea, ni se miraban, y uno dice: ipero si eran hermanos o amigos! Cuando uno sale como para un momento de ocio, o sea, de entretención, no hay cosa más chévere que hablar con una persona. Yo, a veces, prefiero gastar un minuto y hablar con una persona que estar ahí pegado del celular porque esa dependencia no me parece. Me parece importante el celular por lo que hemos coincidido de la llamada y todo el cuento, pero hasta cierto punto; hay que saber en qué momento ya deja de ser personal y se convierte en impersonal. (G. 3, p. 4, r. 1)

Sin embargo, cuando se suscitaron algunas discusiones sobre las relaciones de pareja los estudiantes manifestaron con mucha más vehemencia sus reparos hacia la comunicación digitalmente mediada. Pareció, incluso, que era ahí donde ellos advertían un mayor riesgo de banalización. Esto tal vez se explique por el hecho de que en este tipo particular de relaciones se espere un contacto interpersonal mucho más íntimo y emocionante.

Los discursos sobre la mediación de las tecnologías digitales en las relaciones sentimentales coinciden, en primer lugar, en denunciar lo molesto que resulta pasar tiempo en pareja cuando uno de los dos está ocupado con su teléfono móvil.

-(...) el tema del respeto, por ejemplo hacia la pareja. El hecho de que cada uno esté en sus cosas con el celular, para mí eso es una falta de respeto. (G. 3, p. 7, r. 5)

-(...) cuando salgo con alguien y están chateando me pone de mal genio porque no me ponen atención, y están es hablando 
con otras personas. No me gusta y además no tengo celular. (G. 6, p. 1, r. 9)

En segundo lugar, sus aportes dejaron ver que los ritos de acercamiento y de conquista se han transformado. Descripciones como las que siguen evidencian cómo, desde su perspectiva, las primeras fases de las relaciones sentimentales se han vuelto triviales:

-Las relaciones amorosas son como muy superficiales, uno ya se habla con alguien, entonces comienza a hablar toda la semana y iya! A la semana [dice]: “ino, te quiero!”. Pero para que uno establezca una amistad tiene que conocerse bien con una persona, conocer como sus intereses, que pase tiempo para que nazca ese sentimiento. Pero dos semanas y que le digan: "me gustas"... O sea, es algo como que no tiene sentido. O veámonos y iya!: "relación” en 'Face'... Como que le quitan la importancia a lo que hacen. Antes se tomaban el tiempo de conocerse y en esa parte uno es el culpable del uso que le da [a la tecnología].

-Antes para dedicar una canción, era en un casete y ahora que un enlace; o [antes] una carta en papel y ahora que un mensaje. La comunicación se ha vuelto eso. (G. 1, p. 16, r. 16 y 18)

En tercer lugar, destacan las diferencias entre las reflexiones de chicos y chicas sobre sus experiencias con las tecnologías digitales en sus relaciones de pareja. Mientras que los muchachos tendían a valorar la facilidad que ofrecían móviles, aplicaciones y redes sociales a la hora de atender las demandas de comunicación de sus parejas, las chicas reclamaban ante lo que consideraban una comunicación mediocre y disociada. Según ellas, las charlas con sus parejas masculinas cambiaban radicalmente según acontecieran presencialmente o en modo online. Obsérvense, pues, las diferencias entre chicos y chicas:

(Chicos)

-Yo digo que también [hay influencia de] la pareja con el celular porque hay que hablar con ella (...). 
- Cuando tienes la necesidad de compartir entonces llamas o escribes por el celular; es como una necesidad de ella [de la pareja].

-O sea, cuando uno está ocupado puede hablar con ella, no es necesario tenerla al frente: chateas o hablas. (G. 4, p. 2, r. 5-7)

\section{(Ghicas)}

-En cuanto a novio, pues es que no sé. Todo mundo tiene pin o WhatsApp, [ellos] no quieren llamar, se pierde eso. Entonces [dicen]: "¿para qué nos vamos a ver? No, hablemos toda la tarde por ahí”. Entonces, ya como que el contacto cambia.

-Sí, yo creo que es así porque se muestran como no son, pero cuando es frente a frente ya no hay casi expresión, entonces se pierde como eso. (G. 2, p. 5, r. 5 y 13)

-A veces muchos amigos les hablan a las niñas superbien, les hablan y las conquistan, pero cuando las conocen físicamente es otra cosa; no pasa nada. (G. 2, p. 4, r. 12)

\section{Los actores y su conflicto}

En el Capítulo 3, se decía que la construcción identitaria resultó ser una cuestión especialmente relevante para los participantes, en la que convergieron asuntos como la globalización, el acceso a la información y la comunicación mediada digitalmente. La construcción de la identidad, por tanto, permitió apreciar los vínculos entre los imaginarios de los estudiantes sobre el mundo actual y el lugar que ellos dicen ocupar en él.

En esta sección se toma como referencia lo expresado por los participantes sobre la construcción de la identidad para ahondar en los modos como ellos, en tanto jóvenes y estudiantes, se describieron a sí mismos. Esto implica profundizar en algunos hallazgos y conclusiones que se plantearon antes y que podrían ser vistos como los grandes conflictos que enfrentan los jóvenes (al menos los 
participantes) en tanto que actores sociales/educativos. Por tanto, hay que volver sobre la cuestión de la ambivalencia del relato estudiantil y sobre cómo ellos se entienden a sí mismos como sujetos a medio camino entre la autorregulación y la heteronomía, entre el desencanto y la promesa tecnológica.

\section{Los jóvenes/estudiantes según ellos mismos}

En principio, los participantes se definieron a sí mismos como sujetos de una época en la que las tecnologías introducen una promesa de autonomía y progreso. Los estudiantes se describieron, por tanto, como parte de una generación afortunada, que puede desarrollar sus capacidades humanas gracias a la tecnología. No obstante, dejaron entrever que la promesa de un futuro mejor por cuenta de las tecnologías no se dirige en principio a ellos mismos en tanto que jóvenes, sino que pareciera realizarse, sobre todo, en los niños. De hecho, pese a que reconocen su vínculo estrecho con las tecnologías digitales, pareciera que los participantes no se ven a sí mismos como nativos digitales (Prensky, 2001). Ese mote, según ellos, caracteriza mejor a sus hermanos, primos o sobrinos de menor edad, pues a su juicio son los niños quienes están realmente mucho más embebidos en universo digital. De ello dan cuenta las siguientes opiniones:

-Yo creo que ha cambiado el mundo como en el sentido de que las personas se vuelven más intelectuales, con más capacidad de crear y crear más cosas. Le das por ejemplo una Tablet a un niño chiquito y la maneja superfácil. En cambio, nosotros aprendimos porque nos tomamos el tiempo de ver cómo funcionaba. Ahora los niños salen más inteligentes, uno se pone a pensar cómo serán después. (G. 2, p. 5, r. 5)

-(...) mi hermanita de tres años cuando se la deja se sabe meter a todo, se sabe meter a juegos o a lo que le interese. (G. 2, p. 5, r. 6) 
Poco a poco, iba quedando claro que los participantes se veían a sí mismos como algo diferente a una generación digital. En sus discursos se advertía una intención franca por desmarcarse tanto de los adultos como de los niños. Parecía, pues, que su conciencia generacional tenía que ver, más bien, con ser un estadio intermedio y conflictivo entre los mayores - poco competentes en asuntos tecnológicos pero maduros-, y los niños -más hábiles y adaptados, pero menos reflexivos-. Esto se advirtió en frases como los que vienen a continuación:

-Otra cosa que me parece importante es que la brecha tecnológica que hay entre una generación no tan anterior y la nuestra es muy marcada. Mis papás, por ejemplo, no son personas tan mayores, pero el desconocimiento que hay de parte de ellos es complicado (...) nosotros nacimos y no hubo una transición amable del espacio tecnológico, sino que entró con fuerza, poco controlado. (G. 7, p. 5, r. 3)

-Yo creo que en eso [el juego] sí ha cambiado demasiado. Uno de pequeño no conocía la tecnología y salía a jugar a la calle (...). A mí me parece impresionante que niños que cuando yo jugaba con comida ya tienen Facebook. Y uno dice: "qué bueno, tienen amigos, juegan". Pero como tal no saben para qué se utiliza el Facebook aunque ya lo tienen ahí. Incluso así de grandes ya también han cambiado las cosas porque digamos: uno puede salir a jugar; yo personalmente todos los sábados salgo a jugar fútbol, pero salgo a jugar si no estoy conectado. Igual yo me conecto y me da pereza salir porque quiero quedarme ahí con eso conectado. (G. 1, p. 17, r. 1)

En síntesis, los estudiantes destacaron la capacidad de las nuevas generaciones de adaptarse fácilmente a las tecnologías, al tiempo que se refirieron a la madurez y al criterio de los adultos, en particular de sus profesores, como algo igualmente deseable. Si bien la influencia de los maestros se abordó en el capítulo anterior, vale la pena reseñar algunas intervenciones que evidencian que, en buen grado, las reflexiones más críticas de los participantes sobre 
sí mismos y sobre las tecnologías digitales provienen de su contacto con el mundo adulto, y en particular con sus profesores. Estas son algunas muestras de sus aportes:

-(...) la madurez, eso también influye. Yo tengo recuerdos muy vagos de lo que me haya dicho un profesor, pero de lo que recuerdo es que el Internet es una herramienta que tiene muchísimas cosas, todo se encuentra ahí; pero no todo es bueno para nosotros y no es bueno pasar demasiado tiempo frente a un computador. Y pues la mayoría [de jóvenes], pero no digo que todos, están haciendo una tarea y también están en Facebook, y entonces les hablan y ya no están haciendo la tarea, sino que se van a mirar el Facebook, se quedan 20 minutos y luego sí vuelven a hacer la tarea. Pero ellos [los profesores] en cambio pues tienen como la madurez y el control de sí mismos para saber que si están haciendo una cosa es haciendo una cosa, no como nosotros [los jóvenes] que estamos más distraídos. (G. 6, p. 4, r. 2)

-Pues de los profesores pienso que ellos creen que el Internet como tal, como comunicación es excelente, y para aclarar un concepto sirve, pero que tiene desventajas (...) nosotros nacimos con el Internet; muchos profesores que ya tienen su edad, ellos no tienen esa necesidad, ellos no conocen de computadores desde pequeños. En cambio, nosotros nacimos con eso, es como un hábito de estar nosotros metidos en el Internet; en cambio, él tiene esa madurez de saber a qué van al Internet y lo usan diferente. Nosotros usamos Internet para todo, sí, es como la forma de comunicación y para nosotros funciona. [El Internet] es para todo, nosotros pasamos nuestra vida en Internet. Para conseguir esa madurez no la vamos a conseguir tan fácil, será a medida del tiempo (...). (G. 6, p. 4, r. 8)

-Yo pienso que nosotros frente a las tecnologías somos muy inmaduros como, por ejemplo, en un celular. A muchas personas que tienen pin se les olvida el entorno y por eso hay accidentes, eso dicen los profesores y pues en eso estamos de acuerdo totalmente. (G. 6, p. 5, r. 5) 
-(...) en una reunión familiar uno ve a los menores de 25 años pegados a un celular chateando, y los demás y la gente más madura están es conversando de otra manera. Entonces [la tecnología] sí las afecta [las relaciones sociales] y mucho. (G. 10 , p. 4, r. 1$)$

Las referencias al mundo adulto indicaban que, si por un lado el mundo actual y las tecnologías entrañan ciertas promesas, por otra parte también se corre un riesgo de ir a la deriva. Es decir, al tiempo que los estudiantes se definieron a sí mismos como una generación privilegiada en lo que atañe al acceso a tecnologías, información y nuevas formas de comunicación, también insistieron en la madurez que resulta necesaria para sacar provecho de todos esos beneficios potenciales. De hecho, como se puede apreciar, el mero contacto con las tecnologías no garantiza un uso adecuado de las mismas. Se advierte, incluso, que una cercanía irreflexiva con ciertos dispositivos puede resultar contraproducente:

-En un principio estas tecnologías se utilizaron como una herramienta que ayudaba a ampliar los conocimientos. El problema es cuando estos jóvenes se acostumbran a copiar estos conocimientos sin analizarlos ni usar un criterio adecuado: esto representa que hoy en día todos los jóvenes utilizan estas herramientas (...). Bueno, esto empezó como una herramienta de ampliación de conocimiento, ahora los está limitando [los conocimientos]; o sea, [los jóvenes] no están analizando ni prestando atención a lo que leen o lo que ven, sino que simplemente lo copian. (G. 10, p. 2, r. 1)

- (...) porque como todo está tan cerca, como todo está tan fácil de encontrar, los estudiantes ya no tienen ese interés por encontrar las cosas, por saber. [Los estudiantes no tienen el interés] por querer saber, por aprender por ellos mismos, sino por hacer una tarea o cumplir ciertos parámetros que se les exige. El problema es que se les elimina esa capacidad, el interés y la autonomía, y cuando se les termina eso, se termina la base del conocimiento. (G. 11, p. 2, r. 4) 
Los participantes insistieron en la importancia de establecer principios rectores que les sirvieran como referencia para un uso maduro y reflexivo de las tecnologías digitales. Esto resultó tan importante para ellos que, por tanto, constituye un rasgo característico en sus definiciones sobre sí mismos. Los jóvenes no se autodefinen solamente como sujetos a caballo entre la novedad y el pasado, o entre el mundo adulto y el infantil; también se describen a sí mismos como seres en busca de madurez y reflexividad, al ser estas, según ellos, herramientas de afrontamiento de la ambivalencia que atraviesa su experiencia con las tecnologías digitales.

\section{Hacia la resolución del conflicto: entre el fuero individual y las mediaciones culturales}

Si el conflicto que define el discurso de los estudiantes como actores es, precisamente, la ambivalencia del mundo, de la comunicación y de las tecnologías, el modo de resolverlo es también de doble vía. Por un lado, los participantes reivindicaron fuertemente lo que aquí se denominó "fuero individual", es decir, el criterio personal y original como ámbito de discernimiento sobre el papel que ocupan las tecnologías y los usos que se antojan adecuados y constructivos. Por otra parte, los estudiantes reconocieron la necesidad de buscar mediaciones culturales externas que les sirvan como repertorio normativo y valorativo en su relación con las tecnologías digitales. Si por un lado los participantes insistían en que cada quien debía encontrar el modo de darle un uso adecuado a los dispositivos digitales, por otro señalaban que todo no dependía de ellos mismos, y que por lo mismo necesitaban salir de sí mismos en busca de unas pautas de juicio alternativas a las que ya poseían.

Cuando se solicitó a los estudiantes que describieran los términos en que se podría construir una relación ideal con las tecnologías digitales se pudo notar que, en principio, ellos otorgaron 
bastante relevancia a la iniciativa y el criterio individuales. Según ellos, el efecto que producen las tecnologías digitales depende ante todo de la persona que las usa. El recurso, por momentos casi que retórico, al fuero individual como solución se aprecia en las siguientes intervenciones:

-Nosotros debemos saberlos manejar y saberlos utilizar para un bien propio y para el bien común. (G. 1, p. 7, r. 3)

-Internet es como entrar a otras culturas. Aunque ya depende es del uso que uno le esté dando, porque uno a veces como que lo está usando por usarlo. (G. 1, p. 8, r. 2)

-Yo digo que es bueno y es malo si uno sabe manejar lo que hace en Facebook. (G. 1, p. 16, r. 17)

-Yo considero que eso va es en cada uno. Digamos, si yo digo que no quiero ser tan dependiente de la tecnología no lo hago, y uno le da un uso apropiado a la tecnología. No se puede decir que por culpa de la tecnología la sociedad está como está, no. Eso depende de la sociedad, de cómo le dé uso a la tecnología. (G. 1, p. 14, r. 2)

-Uno controla hasta dónde llega la tecnología, que no tiene límites. En mi concepto la gente establece los límites, no la tecnología. (G. 3, p. 3, r. 5)

-Sí, uno nota que ahorita uno vive del tema del computador y el Smartphone, pero eso va muy ligado a los valores que tiene uno.

-La tecnología está ahí y tú decides qué uso le das: si le das un uso positivo, chévere; o si le das un uso malo, pues traerá consecuencias para ti, para tu familia, para la sociedad, para quienes te rodeen. (G. 3, p. 7, r. 5 y 7 )

-Las TIC nos generan muchas alternativas y pues ya depende de la persona si las utiliza para eso o no; eso va enfocado hacia la persona. Las TIC no serían nada si la persona no estuviera, entonces la persona es la que se encarga de darle [el rumbo]. 
Si las oportunidades son para bien o para mal eso depende del uso que le dé la persona. (G. 7, p. 4, r. 4)

-(...) yo creo que Facebook y todo eso es como un arma; el arma en sí no es más que un objeto; es lo que hacemos con ella. (G. 7, p. 9, r. 4)

También se pudo advertir que cuando los estudiantes se referían al fuero individual destacaban ciertas actitudes que consideraban deseables, tales como la moderación, el discernimiento de la información y la responsabilidad, etc. Esto fue lo que dijeron:

-Uno no puede decir que las tecnologías van a perjudicar totalmente a la sociedad porque en cierta parte le facilitan algunas cosas que se le complican más. Ya depende del uso que uno le quiera dar, porque nos hemos vuelto muy conformistas, entonces ya está el Internet y la gente de ahí saca todo. Entonces, hay que ir más allá, esforzarse por hacer las cosas, porque entonces uno se vuelve facilista. (G. 1, p. 14, r. 4)

-Yo creo muy importante la moderación: como todo en la vida [todas las cosas] en exceso son malas. Si no se tiene controlado eso de las redes sociales (...). Entonces, tendríamos que ser conscientes de lo que estamos haciendo, ser conscientes de la información que uno está recibiendo y la que está dando. (G. 9 , p. 7, r. 1)

-(...) uno tiene que abrirse a buscar todo tipo de información, de ver lo que está leyendo y con qué se queda. Así sí puede hacer un constructo más apropiado a los intereses personales que tiene uno. (G. 10, p. 7, r. 2)

-Yo creo que las TIC y todo eso de las comunicaciones e Internet debería fundamentarse en tres aspectos: equidad en el acceso, uso responsable [no creo que limitación], y en el respeto. (G. 10, p. 8, r. 4)

-Yo creo que un valor muy importante es la responsabilidad. Como decía la compañera: la autonomía también para distinguir 
qué es mejor para mí porque uno por tal lado aprende y listo, pero no es enriquecimiento. (G. 11, p. 7, r. 5)

No obstante, también se pudo observar que los estudiantes hacían hincapié en el valor de la educación y de una nueva cultura de los medios digitales. Al tiempo que se reivindicaba el juicio individual, los participantes afirmaban que no todo dependía de sí mismos, sino que también era necesario posicionar en un nivel intersubjetivo otro tipo de significados que permitieran una experiencia más significativa, menos banal con las tecnologías digitales. Esto con el fin de que se las viera como algo más que meros instrumentos de entretenimiento y de consulta ocasional. Todo ello, afirmaron, resultaba especialmente relevante sobre todo en el caso de las nuevas generaciones, que contaban con un acceso y unas habilidades aceptables en el uso de dichos dispositivos, pero que requerían, sin embargo, formar su criterio y su sensibilidad. Como consta en los extractos que vienen a continuación, algunos de ellos indicaron que era en el plano educativo donde se podía producir algún cambio en los criterios que impulsan los usos corrientes (y potencialmente nocivos) de las tecnologías digitales.

-Internet es bueno si uno lo sabe usar, pero nosotros no sabemos usarlo, por eso nos hace tanto daño; con la forma en la que lo utilizamos no hay crecimiento ni de la mente ni del cuerpo ni nada. Hay muchachos que juegan basquetbol en Internet, tenis en el computador, y luego salen con una raqueta y pues no ven una. (G. 6, p. 5, r. 2)

-(...) el sistema educativo no nos está preparando para ese uso crítico del Internet. Yo creo que ese flujo de información puede ser tan oportuno como también nocivo. ¿Con qué criterio accede uno a esa información que le dan? [Las tecnologías digitales] contribuyen en cuanto al acceso de información: se accede a más cosas, más libros, pero se quedan en que hay un sistema educativo que no responde a ese flujo de información. (G. 7, p. 4, r. 9) 
-(...) el principal problema es que no nos están enseñando a usar el Internet. Nadie nos enseñó a utilizar educativamente estos medios, el Internet; no nos enseñaron, nosotros hemos aprendido empíricamente, solos, al enfrentarnos al Internet. Nos tocó solos y nos tocó utilizarlo sobre lo que hemos aprendido y pues uno aprende por medio del entretenimiento. (G. 7, p. 5, r. 1)

-Como aspecto a mejorar: hay que inculcarles a los estudiantes esa posición por estar informados por temas de su interés, que le nazca ir a buscar todo eso; es como para mejorar. Y pues en el proceso formativo sería como pues desde que esté pequeño el niño que tiene que estar con los temas de interés de él, informarse de esos temas, que sepa dónde ir a buscar, que la familia lo haga, los profesores, amigos; como el vínculo social. (G. 8, p. 4, r. 1)

El hecho de que los estudiantes reclamen más acompañamiento y dirección por parte de la Universidad y de los maestros indica que, para ellos, ambos tienen un papel sumamente relevante. Esto se evidencia con más claridad en las intervenciones que siguen, pues permiten apreciar cómo, para los participantes, la educación formal constituye un nicho privilegiado para poder reconfigurar su relación con las tecnologías digitales y, de ese modo, enfrentar con más acierto los retos éticos y culturales del mundo actual:

-Sí, deberíamos tener un nivel de educación, de cultura, más elevado para poder llegar como a una buena utilización de la tecnología. (G. 1, p. 7, r. 1)

-(...) para generaciones como nosotros y las que vienen, que ya se tiene un uso constante de este tipo de cosas, la misma educación nos va planteando estos principios. Nosotros veníamos del colegio utilizando esto de las TIC como por entretenimiento. Hoy la Universidad ya lo hace de otra manera y por eso chocamos o fallamos tanto. Nos están enseñando tarde, pero nos están enseñando cómo utilizarlas (...). Hay tiempo para entretenerse, sí, pero también [enseñar] cómo se usa una herramienta y para qué. 
-La principal [condición]: la educación y la capacitación de todas las personas. Digamos: las personas mayores que se instruyan de estas tecnologías porque tienen la necesidad ahora; y a los niños que se les enseñe cómo utilizarlas. (G. 9, p. 7, r. 3 y 4)

-(...) [se debería] informar a las personas de los peligros que se pueden encontrar no solo en Internet, sino también en los medios de comunicación. (...) crear una consciencia del peligro [que existe]; que se tengan tutores en ese mundo que es muy abierto. (G. 10, p. 8, r. 7)

-(...) que se impartan cátedras para el buen manejo de las tecnologías, que sea una buena herramienta para lo que hemos dicho: unas buenas relaciones sociales y buenos escenarios multiculturales y que no se presenten para discriminar minorías.

-(...) que la persona cuando se enfrente a las TIC diga lo que puede ser moralmente bien y qué puede ser moralmente malo, qué puede afectar la dignidad de la persona y qué no. (G. 11. p. 7 , r. 1 y 4 ) 